\title{
A INOVAÇÃO NO CONTEXTO DA SOCIEDADE DA INFORMAÇÃO
}

THE INNOVATION IN THE CONTEXT OF THE

1Kilma Gonçalves Cezar

2Emir José Suaiden

Universidade de Brasília1, 2

\section{Correspondência}

Kilma Gonçalves Cezar

Universidade de Brasília

Brasília, DF - Brasil.

E-mail: kilmagc@yahoo.com.br

iD ORCID: https://orcid.org/0000-0002-5960-8585

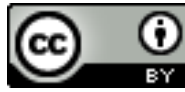

JITA: BG. Information dissemination and diffusion.

e-Location: 019026 


\section{RESUMO}

O presente artigo se propôs a lançar luz sobre a importância de se publicizar o processo de inovação no Brasil, trabalhando a seguinte ideia: a coleta e a gestão de informações e de conhecimento do cidadão comum podem se revelar uma ferramenta destinada à ampliação da capacidade inovativa do País. Para tanto, foi realizada breve revisão da literatura acerca da dinâmica contemporânea característica do novo paradigma econômico-tecnológico da informação, foram levantados estudos sobre o envolvimento do cidadão comum no processo de inovação, e foram discutidos modelos desenvolvidos voltados para a sistematização da inovação. Os autores concluem que o Brasil ao deixar de publicizar a inovação, ou seja, de contemplar o fluxo livre e público de ideias, de informações e de experiências pode estar deixando de impulsionar seu potencial de inovação.

\section{PALAVRAS CHAVE}

Informação. Inovação. Cidadão.

\section{ABSTRACT}

This article aims to call attention to the importance of publicizing the innovation process in Brazil by working with the following idea: the collection and management of information and knowledge of ordinary citizen can be seen as a tool to increase the innovative capacity of the country. A short review of the literature on the contemporaneous dynamics characteristic of the new economic-technological paradigm of information was carried out, studies were collected on the involvement of the ordinary citizen in the innovation process, and models developed aimed at the systematization of newness were disputed. The authors conclude that Brazil, by not publicizing innovation, that is, to contemplate the free and public flow of ideas, information and experiences may be faling to promote its innovation potential.

\section{KEYWORDS}

Information. Innovation. Citizen 


\section{PDO- Revista Digital Biblioteconomia e Ciência da Informação

\section{Introdução}

No mundo contemporâneo concebido a partir do novo paradigma econômicotecnológico informacional cuja lógica está na criação, gestão, disseminação e apropriação de informações, ideias e conhecimentos, a participação do cidadão comum no tratamento de temas como a inovação, no caso deste artigo, a publicização da inovação, pode se revelar uma ferramenta facilitadora para a ampliação da capacidade inovativa do País.

Esse novo paradigma informacional, o qual fundamenta a sociedade da informação, está associado à reestruturação e expansão do capitalismo, e sua lógica está na alta penetrabilidade da informação, do conhecimento e da inovação nas relações econômicas, sociais e humanas; na estrutura organizada em redes sociais e eletrônicas; na reversibilidade dos processos e produtos a partir do uso de tecnologias; na globalização das atividades econômicas e na convergência de tecnologias envolvendo diferentes áreas de conhecimento (CASTELLS, 1999).

Trata-se, segundo Castells (1999), da transição entre duas formas diferentes de produção, a baseada na economia de escala, redução de custos e ganhos de produção conhecida por industrialismo e a outra, baseada na aplicação mais intensiva da informação e do conhecimento nos processos produtivos, o informacionalismo. Para o autor, essa transição se traduz na nova economia, intitulada economia informacional cuja característica está na centralidade e na aplicação de conhecimentos, ideias e informação na geração de novos produtos e serviços.

Quanto à publicização da inovação, é tema recorrente em estudos como alguns abaixo citados, os quais tratam da importância do acesso e da valorização da participação do cidadão comum, por meio de modelos que contemplem o fluxo livre de informações, ideias e conhecimentos, formados nas práticas histórico-sócio-culturais, frente ao processo de inovação.

Mueller (2002) assegura que a veiculação dos resultados de pesquisas científicas e tecnológicas, e o acesso às ideias e questionamentos do cidadão comum são fundamentais para se ampliar a consciência sobre o que é ciência, tecnologia e inovação, bem como sua importância no dia a dia das pessoas. E essa interação com o público estabelece vínculos entre ciência, saberes e valores culturais, e estes podem revelar descobertas inovativas.

Esse entendimento é reforçado por Suaiden e Leite (2016) quando afirmam que a trajetória do desenvolvimento de uma sociedade se inicia quando o homem amplia a consciência a partir do acesso ao conhecimento. E, que, independente das diferenças culturais e níveis de desenvolvimento alcançado pelos cidadãos e pelas sociedades, a ciência e a tecnologia segregam, congregam, excluem e incluem, refletem e propiciam a evolução da humanidade. 
A publicização da ciência, tecnologia e inovação encontra amparo no relato do professor Ildeu de Castro Moreira em palestra ministrada na Semana Nacional de Ciência e Tecnologia (SNCT), em 2015 ${ }^{1}$, quando assegura que as pessoas valorizam e têm interesse na ciência e na inovação tecnológica, sendo necessário, portanto, aprender a conversar e a mostrar ao cidadão comum que ciência, tecnologia e inovação são construções coletivas e sociais.

A preocupação com a publicização da ciência, tecnologia e inovação encontra ressonância na chamada "Ciência Cidadã" a qual consiste na participação do cidadão no processo de investigação e de produção científica (HAKLAY, 2013) ${ }^{2}$. Apesar de lançar mais luz sobre a participação das populações locais em iniciativas de conservação da biodiversidade, os projetos de Ciência Cidadã propiciam o envolvimento efetivo do cidadão em toda a cadeia da pesquisa e da produção científica, o que permite uma apropriação do conhecimento, gerado pela pesquisa, e de seus resultados.

Nesse sentido, entende-se que a participação, a interação e o envolvimento do cidadão na produção e em pesquisas científicas e tecnológicas permitem integrar a ciência e a tecnologia na cultura popular promovendo a participação cidadã, ou ainda, a inclusão social em temas de CT\&I.

E essa inclusão se traduziria na transposição das idéias contidas em pesquisas científicas e tecnológicas para os dia a dia das pessoas, fazendo com que fenômenos e métodos científicos e tecnológicos se tornem assuntos de opinião, comportamento, cultura e de debate público.

Entretanto, ao se procurar dados e indicadores sobre o status do acesso da sociedade às produções e às informações científicas e tecnológicas, bem como à inovação, verifica-se que este não é representativo.

De acordo com a Pesquisa Nacional da Percepção Pública da Ciência, promovida em 2010, pelo então Ministério da Ciência e Tecnologia - MCT, das 2.016 pessoas entrevistadas, em diversas partes do país, $19 \%$ informaram que assistem a programas de televisão que abordam temáticas voltadas para o campo científico, $14 \%$ leem jornais que abordam o assunto e $13 \%$ fazem uso de revistas e também da Internet para a busca de informações científicas e tecnológicas, representando com isso uma ampliação significativa desse acesso considerando a mesma pesquisa realizada em 2006 onde $9 \%$ usavam a Internet para buscar informações sobre ciência e tecnologia e $15 \%$ faziam uso da televisão para este fim.

\footnotetext{
${ }^{1}$ http://www.mcti.gov.br/noticia/-/asset_publisher/epbV0pr6eIS0/content/tema-da-snct-2015-remete-ao-anointernacional-da-luz

${ }^{2}$ Vale salientar o trabalho desenvolvido pelo grupo Ciência Cidadã Extrema (ExCiteS), composto por pesquisadores de diferentes disciplinas acadêmicas, cujo objetivo consiste em desenvolver e contribuir com teorias, ferramentas e metodologias que orientem e habilitem qualquer comunidade a iniciar um projeto de Ciência Cidadã para lidar com as suas questões. http://www.sibbr.gov.br/cienciacidada/. Acesso em: jul. 2019.
}

\begin{tabular}{l|l|l|l|l|l|}
\hline (c) RDBCl: Rev. Digit. Bibliotecon. Cienc. Inf. & Campinas, SP & v.17 & $1-21$ & e019026 & 2019
\end{tabular}


Atesta-se assim que o acesso às informações de cunho científico e tecnológico por parte da sociedade tem avançado, mas que os números ainda são pouco representativos. Constou da conclusão da pesquisa que as discussões sobre ciência, tecnologia são restritas aos fóruns acadêmicos e aos órgãos governamentais.

Quando se consulta sobre os indicadores de inovação no País, verifica-se que o Brasil tem se mantido em um contexto de pouco êxito no desenvolvimento a partir de iniciativas inovadoras.

Segundo estudo realizado pelo Fórum Econômico Mundial, o Brasil saiu da 50 a posição para a $68^{\mathrm{a}}$ no ranking mundial da inovação, e em relação aos países latino-americanos caiu da $3^{\mathrm{a}}$ para a $7^{\mathrm{a}}$ posição ${ }^{3}$.

Quanto ao Sistema Nacional de Ciência, Tecnologia e Inovação - SNCTI, apesar de ter evoluido de uma estrutura simples, baseada em agências de fomento para uma estrutura complexa e com capilaridade considerando seus ministérios, secretarias, institutos de pesquisa, universidades, empresas e outras instituições, verifica-se que essa evolução ainda não se traduziu em avanços efetivos de apoio à inovação no País. $\mathrm{O}$ investimento em pesquisa e desenvolvimento (P\&D) proporcional ao PIB referente ao ano de 2016, representou 1,24\%, tendo avançado apenas $0,2 \%$ desde $2000^{4}$.

E, em relação ao meio acadêmico, onde as descobertas são, geralmente, desdobradas em dissertações e teses, verifica-se que, poucas vezes estas geram benefícios à sociedade a partir da aplicação do conhecimento ora produzido na inovação de produtos e serviços. Conforme dados divulgados pela Pesquisa de Inovação Tecnológica do IBGE - PINTEC 2008, o Brasil produz um volume de conhecimento científico (medido pelo número de artigos) assimétrico em relação à inovação (medida pelo número de patentes depositadas).

Ao se buscar um posicionamento técnico acerca desse contexto, verificou-se que a inovação tecnológica, enquanto provedora de produtividade e desenvolvimento, tem sido tratada como oriunda da parceria universidade/empresa, e que alguns dos principais obstáculos para o incremento das forças inovadoras brasileiras se concentram na incapacidade das instituições de administrarem processos inovadores, uma vez que mantêm a burocracia e a ineficiência da prática da gestão da inovação ${ }^{5}$.

\footnotetext{
${ }^{3}$ Ver http://www.bbc.com/portuguese/noticias/2010/03/100305 inovacao_relatorio_vdm.shtml, Acesso em: maio 2017.

Ver https://www.globalinnovationindex.org/gii-2016-report, Acesso em: maio 2017.

${ }^{4}$ Ver http://irisbh.com.br/indice-global-de-inovacao-2016/

${ }^{5}$ Ver artigo da BBC na íntegra file://C:/Users/wilson/Downloads/artigo.pdf Acesso em: maio 2017.

\begin{tabular}{l|l|l|l|l|l}
\hline (C) RDBCl: Rev. Digit. Bibliotecon. Cienc. Inf. & Campinas, SP & v.17 & $1-21$ & e019026 & 2019
\end{tabular}
}


Sendo o gerenciamento da inovação entendido como atividade que permite à organização fazer melhor uso da ciência e tecnologia, gerada interna ou externamente (COTEC, 1999).

Diante desse contexto, onde de um lado há o novo paradigma econômico-tecnológico informacional no qual é imposta a geração de novos conhecimentos e inovação para o alcance do desenvolvimento, do outro, estudos que apontam para a importância de se valorizar a participação do cidadão comum na criação de ideias inovativas, e por último, dados estatísticos que sinalizam a dificuldade do Brasil no alcance do desenvolvimento a partir de iniciativas inovadoras é que se encontra o interesse em trabalhar com o tema: a publicização do processo de inovação impactando a capacidade inovativa do País, no contexto da sociedade da informação.

O artigo está estruturado em três partes: a primeira parte contempla uma breve revisão comentada acerca do advento do novo paradigma econômico-tecnológico da informação, sem a pretensão de esgotar o debate, mas sim de destacar passagens consideradas importantes. A segunda apresentará alguns estudos que amparam a ideia da importância do envolvimento do cidadão comum no processo de inovação. Na terceira e última parte, será abordado o processo da inovação.

Vale esclarecer que, para compreender e explicar o objeto de estudo pretende-se utilizar como método de análise um procedimento interdisciplinar aplicando-o no cotejamento de textos e autores que tratam da temática.

A metodologia consiste no recurso à literatura pertinente, pesquisa documental, de matérias e artigos de revistas buscando incluir aportes dos autores ora citados. Pretende-se a partir da revisão da literatura discutir os dados levantados e extrair entendimentos que possam contribuir para a compreensão e explicação do objeto de pesquisa. Esse método tem relação com a pesquisa qualitativa exploratória a qual segundo autores como Gil (2002) e Malhotra (2001), a qual proporciona a partir de pequenas amostras, percepções e compreensões do problema e de suas subjetividades, bem como a explicação de fenômenos que não eram considerados, apesar de evidentes. Gil (2002) defende que a pesquisa qualitativa com enfoque exploratório é um método de investigação utilizado para compreender o problema e os fatores subjacentes a ele. A visão de Malhotra (2001) contribui com essa linha de pensamento, pois para a autora a pesquisa qualitativa é definida como uma técnica de “... pesquisa nãoestruturada, exploratória, baseada em pequenas amostras, que proporciona insights e compreensão do contexto do problema que está sendo estudado" (MALHOTRA, 2001, p. 155).

Assim, seguindo essa linha metodológica, entende-se que a pesquisa qualitativa exploratória proporciona melhor visão e tratamento do objeto de estudo, e representa um importante meio para compreensão de aspectos subjetivos, uma vez que abriga técnicas de 
interpretação que procuram traduzir, decodificar e descrever termos e temas relacionados com o entendimento do objeto de estudo.

\section{O Novo Paradigma Econômico-Tecnológico da Informação}

A expressão 'sociedade da informação' ou sociedade informacional como prefere Castells (1999) passou a ser utilizada para se transmitir o conteúdo específico do novo paradigma econômico-tecnológico da informação cuja estrutura e dinâmica contemporânea são impactadas pela infra-estrutura de informação.

Nessa nova dinâmica, a produtividade e a competitividade de empresas, regiões e nações dependem basicamente de sua capacidade de gerar, coletar, gerenciar e utilizar de forma eficiente a informação e as ideias, baseadas em conhecimentos, na geração da inovação. Trata-se, portanto, de um sistema cujo conhecimento e o gerenciamento de ideias se apresentam como elementos decisivos para a produção de inovações e consequentemente para o alcance de um crescimento com desenvolvimento.

Sem negligenciar a importância dos fatores de produção tradicionais (mão de obra, recursos naturais e capital), sob a ótica da inovação, o conhecimento assume papel preponderante no reordenamento da economia, abrindo novas fronteiras para a busca do desenvolvimento, uma vez que a dimensão econômica passa a demandar a gestão de conhecimento para a produção de novos conhecimentos que possam gerar a inovação tecnológica, de forma a alcançar a criação e distribuição de novas tecnologias e de outras formas de conhecimento envolvendo os setores produtivos ${ }^{6}$ (NICHOSKY, 1999).

Tal abordagem aponta para uma estreita relação entre crescimento e desenvolvimento que ocorrem com a introdução e disseminação de inovações. Logo, o desenvolvimento se caracterizaria pela ruptura do fluxo de produção, a partir de inovações tecnológicas as quais ocorreriam descontinuamente ao longo do tempo. Para Freeman (2002) as instituições que promovem deliberadamente a aquisição e a disseminação do conhecimento promovem mais a inovação, e esta gera maior produtividade e competitividade. E segundo Schumpeter (1982) ao se estabelecer a relação entre inovação e o aumento de produtividade chega-se ao desenvolvimento.

Com isso, a descoberta de estratégias e a construção de ferramentas para o uso eficaz do conhecimento tornam-se cada vez mais importantes para a busca do desenvolvimento. $\mathrm{O}$ poder de idéias criativas e o domínio da informação e do conhecimento estão impulsionando a

\footnotetext{
${ }^{6}$ Engloba todos os setores da economia: agricultura, indústria, bens de capital, de consumo, de serviços, etc.
}

\begin{tabular}{l|l|l|l|l|l|}
\hline (c) RDBCl: Rev. Digit. Bibliotecon. Cienc. Inf. & Campinas, SP & v.17 & $1-21$ & e019026 & 2019
\end{tabular}


nova economia a produzir altas tecnologias e serviços de valor competitivo elevado, interferindo sobre o desenvolvimento de um país (OCDE: 1999; LASTRES, H., CASSIOLATO. J.E., 2003).

Nessa dinâmica contemporânea a inovação pode ser considerada como um dos cernes do processo de desenvolvimento de um país, uma vez que esse desenvolvimento passa a ser alcançado mediante mudanças de dentro para fora, a partir do lançamento constante de inovações no mercado em função da capacitação tecnológica, investimento em pesquisa e desenvolvimento, maior força de mercado e estrutura financeira das empresas e organizações (SCHUMPETER, 1982).

Como conceito de inovação recorre-se a Freitas Filho (2013) que afirma tratar-se da capacidade das pessoas de utilizar seus conhecimentos, habilidades e criatividade na geração de uma mudança que gere uma nova tecnologia, novo produto, ou que altere o status quo de um serviço, produto, ou ainda, na criação de um novo mercado ainda não explorado de forma a impactar positivamente o desenvolvimento da sociedade (Freitas Filho 2013, p.5).

Neste sentido, o desenvolvimento é entendido como resultado do crescimento econômico atrelado à melhoria da qualidade de vida das pessoas. A afirmação a seguir auxilia a compreensão desse processo.

O desenvolvimento deve contemplar as alterações da composição do produto e a alocação de recursos pelos diferentes setores da economia, de forma a melhorar os indicadores de bem-estar econômico e social - pobreza, desemprego, desigualdade, condições de saúde, alimentação, educação e moradia (VASCONCELLOS e GARCIA, 1998, p. 205).

Ao se introduzir as dimensões de bem-estar econômico e social na definição de desenvolvimento os autores Vasconcelos e Garcia (2005) trazem à tona uma abordagem sociológica do desenvolvimento, a qual o defende como uma condição ou processo que proporciona melhorias na qualidade de vida das pessoas e da sociedade em geral, colocando em plano secundário a importância de atributos como posse de recursos físicos, capital e renda.

Sob essa perspectiva, Veiga (2006), seguindo a linha de raciocínio de Amartya Sem (2000), adiciona aspectos da sociologia no entendimento sobre o processo de desenvolvimento, os quais permitem que se lance um novo olhar sobre a questão. Para o autor, a vivência histórico-sócio-cultural do cidadão comum pode ser um contributo à inovação, e o desenvolvimento ocorre quando novas ideias geram mudanças socioeconômicas as quais expandem a liberdade e a capacidade de as pessoas poderem fazer suas escolhas para ser e ter a vida que realmente desejam. Segundo Sen (2000) o desenvolvimento melhora não somente a qualidade de vida, mas também as habilidades produtivas das pessoas e, por conseguinte, a redução de vulnerabilidades sociais. 
Nesse sentido, verifica-se que além do propósito econômico, a participação do segmento social, enquanto meio e fim do processo, também pode ocupar espaço no contexto do desenvolvimento, a partir da inovação. Essa afirmação é reforçada por Dagnino (2009) quando ressalta que o processo de transformação da informação em conhecimento, do tácito para o explícito, do conhecimento em inovação envolve a participação do cidadão comum no que corresponde a seus processos de educação, sua cultura, e práticas gerando, portanto, uma nova dinâmica socioeconômica do desenvolvimento (DAGNINO, R. et alli, 2009).

Seguindo esse raciocínio, verifica-se que a inovação, enquanto processo que considera a atuação do cidadão, se apresenta como uma das molas propulsoras para o alcance da produtividade atrelada ao crescimento, que está atrelado ao desenvolvimento, e este ao bemestar econômico e social.

A FINEP (2000) considera como inovação para o desenvolvimento social a criação de tecnologias, processos e metodologias originais que possam vir a se constituir em propostas de novos modelos e paradigmas para o enfrentamento de problemas sociais, combate à pobreza $\mathrm{e}$ promoção da cidadania.

Para os autores Cezar, Gomes e Persegona (2011) o segmento econômico do desenvolvimento, a partir da inovação, contempla as novas tecnologias e produtos, alcançadas com a disseminação e uso do conhecimento. Enquanto que o segmento social está relacionado à superação de desigualdades e da vulnerabilidade social a partir da criação de emprego qualificado e maior valor agregado na produção (CEZAR, K.G. GOMES, C.B., PERSEGONA, M.F.M , 2011).

Em consonância com esses pressupostos foi cunhado o termo 'inovações sociais' fazendo referência ao alcance do desenvolvimento voltado para a satisfação das necessidades humanas.

Para André e Abreu (2006) inovação social é entendida como uma ação nova, reconhecida socialmente, voltada para a mudança social, a qual contempla a interação com o indivíduo comum.

O Instituto de Tecnologia Social - ITS (2007) defende que ao incluir o termo social à inovação, traz-se a dimensão socioambiental, a construção do processo democrático e o objetivo de solucionar as principais necessidades da população para o centro do processo de desenvolvimento. Segundo Castor (2007, p. 77), inovação social compreende "a busca, descoberta, experimentação, desenvolvimento, imitação e adoção de - arranjos sociais alternativos - para produzir algo", sendo esses arranjos novas formas de se organizar a produção. 
Desta forma, o desenvolvimento estaria associado à convergência entre demandas socioeconômicas e novas ideias e conhecimentos, de forma a alcançar a melhoria das condições da vida, considerando como fator de influência a interação com o cidadão comum.

Diante do exposto, pode-se perceber que as mudanças estruturais provocadas pelo novo paradigma econômico-tecnológico, caracterizado pela transição do industrialismo para o informacionalismo, se constituem em pressupostos e propostas de novas práticas e paradigmas para o enfrentamento de problemas socioeconômicos, e traz como desafio contemporâneo conceber a inovação não apenas como uma invenção tecnológica e comercial, mas também como uma ideia ou conhecimento, oriundos do envolvimento do cidadão, com capacidade de proporcionar melhorias na produtividade do país, agregar valor social e promover qualidade de vida das pessoas, contemplando os anseios dos segmentos social e econômico da sociedade.

\section{O Envolvimento do Cidadão no Processo de Inovação}

A imposição do novo paradigma informacional de se elaborar novas práticas e produtos para o enfrentamento de problemas socioeconômicos, aponta para a necessidade de se pensar em modelos democráticos, os quais valorizem a participação cidadã, na coleta e gestão de informações, ideias e conhecimento.

Nesses modelos democráticos o conhecimento informal, ora adquirido por meio de experiências e por aprendizados não formais, fora da esfera escolar, ganha visibilidade e podese mostrar tão relevante para a resolução de problemas como o conhecimento formal tratado como conhecimento estruturado, gerado por especialistas e instituições do sistema de CT\&I ${ }^{7}$.

Nesse sentido, a adoção de práticas relacionadas ao desenvolvimento da inovação contemplando a participação do cidadão pode contribuir para a ampliação da capacidade inovativa do País, considerando que o amplo acesso às informações, conhecimentos e ideias, e respectiva coleta e gestão podem facilitar a geração de novos produtos e serviços.

A participação do cidadão no processo de inovação encontra amparo teórico em alguns estudos, abaixo citados, que analisaram o processo de geração e compartilhamento de conhecimentos a partir das dimensões espaciais e socioinstitucionais as quais o envolvem, e da importância do conhecimento informal para a geração da inovação.

\footnotetext{
${ }^{7}$ Ver a definição de conhecimentos em CHIARINI, VIEIRA (2012) http://www.scielo.br/scielo.php?script=sci_arttext\&pid=S0034-71402012000100006. Acesso em: maio 2017.
}

\begin{tabular}{|l|l|l|l|l|l|}
\hline (C) RDBCl: Rev. Digit. Bibliotecon. Cienc. Inf. & Campinas, SP & v.17 & $1-21$ & e019026 & 2019
\end{tabular}


No modelo de participação pública, o qual se baseia no compromisso de democratização do conhecimento formal e informal, a ênfase não está unicamente em sua difusão, mas, sim, na forma em que o indivíduo participa suas ideias e conhecimento, como estes são apropriados e integrados a outros saberes e como, a partir dele, se cria novos produtos ou serviços. Assim, a condição necessária para o desenvolvimento encontra-se na valorização do diálogo entre os especialistas e os não-especialistas, bem como na dimensão cultural na qual o conhecimento está inserido (LEWENSTEIN; BROSSARD, 2006).

Nessa perspectiva Suaiden e Leite (2016) cunharam a expressão 'infocultura' ao defenderem que informação e cultura estiveram sempre presentes na compreensão e na análise do fluxo da história da trajetória humana, e que a interação entre elas impulsiona novos saltos para o futuro da humanidade. Para os autores o processo histórico e evolutivo das sociedades é formado a partir de uma sistematização de valores predominantes nas dimensões socioculturais de cada época considerando a inter-relação entre a informação, seu registro, seu processamento, seu uso e sua interação com a cultura presente na constituição e no desenvolvimento da sociedade.

Para Bourdieu (1983) o cidadão comum se relaciona com as condições objetivas e estruturais do espaço social em que vive, agindo por meio de um habitus, entendido como conjunto de valores e costumes que orienta suas práticas.

Seguindo essa linha de raciocínio, recorre-se a Morin (1996) quando esclarece que as ações dos indivíduos incidem sobre a realidade, a qual está em constante movimento, contribuindo para sua manutenção e/ou sua transformação.

\footnotetext{
... a sociedade é, sem dúvida, o produto de interações entre os indivíduos. Essas interações, por sua vez, criam uma organização que tem qualidades próprias, em particular a linguagem e a cultura. Essas mesmas qualidades retroatuam sobre os indivíduos desde que vêm ao mundo, dando-lhes linguagem, cultura, etc. Isso significa que os homens produzem a sociedade, que produz os indivíduos (MORIN, 1996:48).
}

No contexto sociocultural, segundo Albagli e Maciel (2004) o conhecimento diferenciase de acordo com a sua origem. O conhecimento oriundo de comunidades locais é diferente do de especialistas; assim como o de agentes econômicos se difere do dos grupos sociais; o de empresas com finalidade lucrativa do de empresas públicas; o de arranjos regionais do das redes produtivas. Essa diferenciação chama atenção não apenas para as diversas origens do conhecimento formal, mas sim para os resultados dos fluxos de conhecimentos, suas condicionantes, suas interações e seus produtos. Com isso, a adoção de uma nova metodologia de coleta, tratamento e de difusão de informações e conhecimento permite a geração do conhecimento coletivo e da inteligência local. 
Para as autoras Albagli e Maciel (2004) o conhecimento coletivo ocorre quando várias pessoas de uma localidade ou empresa trocam conhecimento, informações e práticas sobre um mesmo produto, formando assim, muitas vezes, uma comunidade para o desenvolvimento de algo. E, a inteligência local se utiliza da territorialidade e do conhecimento local oriundos de experiência originadas de redes de produção local para o desenvolvimento econômico ou social (ALBAGLI, S. MACIEL, M.H., 2004).

De acordo com o Manual de Oslo (2004), fatores humanos, sociais e culturais como as interações informais, a facilidade de comunicação, a cooperação e os canais de transmissão de informações são identificados como de grande importância para o alcance da inovação, pois podem propiciar maior difusão do conhecimento a uma larga escala de indivíduos.

Ao se analisar as determinantes da produtividade verifica-se que a disposição de ambientes livres de hierarquizações para diálogos são facilitadores da troca de conhecimento informal, e a partir da disseminação do conhecimento é possível identificar melhorias contínuas em produtos e processos, traduzindo-se em discretas inovações que impactam a otimização do trabalho e a redução do investimento bruto de capital (SOLOW,R. 1997).

Pressupõe-se assim que, a dimensão espacial composta de suas especificidades sociais, políticas e econômicas gera uma dinâmica inovativa, derivada das particularidades da cultura produtiva e histórica local, o quê por sua vez pode contribuir para a criação de um sistema de inovação local e este pode ter consequências sobre o desenvolvimento socioeconômico.

Essa afirmativa ampara o pensamento de que a valorização das diferenças socioespaciais na coleta, gestão, e uso de informações, ideias e conhecimentos ou seja, a publicização do processo de inovação, pode ampliar o acesso a outros tipos de conhecimento além do conhecimento formal, e isso pode gerar ideias inovativas e estas podem impactar mudanças substanciais na busca do desenvolvimento socioeconômico.

\section{O Processo de Inovação}

O termo nova economia ou economia informacional como prefere Castells (1999) desperta interesse em diversos domínios de atuação, mas exerce interesse particular sobre os que atuam no campo da ciência, tecnologia e inovação - CT\&I. Nessa nova economia o caminho da inovação gera as oportunidades de ganhos econômicos e sociais, e se reforça o entendimento de que gerenciar conhecimento, inovações e mudanças são essenciais ao desenvolvimento.

Para Sveiby (1998) em organizações envolvidas com atividades de ciência, tecnologia e inovação (CT\&I), ou ainda nos ambientes de pesquisa e desenvolvimento (P\&D), onde é

v.17 $11-21 \quad \mathrm{e} 019026$


imposto trabalhar mais rapidamente as transformações provocadas pela adoção de um novo paradigma informacional, é imperativo se gerenciar o processo do intangível: informação, conhecimento e inovação (SVEIBY, 1998).

Nessa perspectiva, Freitas Filho (2013) assegura que para a ocorrência e gestão do processo de inovação é necessário envolver conhecimento, criatividade e empreendedorismo. O conhecimento, por manter relação direta com a inovação, uma vez que não há ocorrência da inovação sobre um assunto se não houver o pleno conhecimento sobre ele. A criatividade, por ser considerada a mola propulsora da inovação, pois sem ela não há como ser efetivada a criação do novo. E o empreendedorismo porque é por intermédio dele que a ideia inovadora é colocada em prática. (FREITAS FILHO, 2013).

Existe outro aspecto relacionado à inovação que é a pluralidade e a diversidade dos envolvidos no processo. As atividades inovativas exigem que "pessoas com diferentes conhecimentos, cultura e perfis atuem em conjunto para se desenvolver a inovação" (FREITAS FILHO, 2013:13).

Em relação aos diferentes conhecimentos, Nonaka e Takeuchi (1997) observam que o processo de criação se dá a partir da interação social entre o conhecimento tácito e o explícito. Sendo este, o conhecimento da racionalidade, da formalidade expresso em números e palavras podendo ser armazenado em livros, apostilas e computadores, e, aquele, o subjetivo, o inconsciente, advindo da experiência e percepção de cada indivíduo. (NONAKA, TAKEUCHI ,1997).

Quanto à pluralidade e diversidade cultural trata-se de uma fonte de dinamismo social e econômico e pode despertar a curiosidade, gerar novas ideias e direcionar uma contribuição útil para a melhoria do estilo e padrão de vida das pessoas. A diversidade cultural apresenta duplo desafio: assegurar a coexistência harmoniosa entre grupos de culturas diferentes e a defesa da criatividade por meio de inúmeras expressões culturais. Nesse sentido, a cultura é importante para a consolidação de uma economia baseada no conhecimento, pois enriquece a condição humana, suscitando a criatividade e fomentando a inovação ${ }^{8}$.

Quanto ao perfil das pessoas que se envolvem com o processo de inovação, Freitas Filho (2013) descreve quatro tipos de perfis: o idealizador (a inovação surge, muitas vezes, de um lampejo/ideia criativo); o refinador (trata da conceituação e da busca de inconsistências das ideias); o experimentador (testa a qualidade/desempenho da idéia antes de ser levada como produto ao mercado); e, o executor (transforma a ideia em negócio) (FREITAS FILHO, 2013).

\footnotetext{
${ }^{8}$ Declaração de Okinawa, julho de 2000, Ver http://www1.folha.uol.com.br/fsp/dinheiro/fi2407200013.htm, Acesso em: 15 jun. 2016.
} 
Assim, é possível conceber a inovação enquanto processo, e passível de gerenciamento, ao invés de se tratar de um evento isolado. Essa percepção encontra amparo no relatório Science, the Endless Frontier, de 1945, autoria de Vannevar Bush o qual difunde a concepção dinâmica da inovação, a partir da utilização de modelos para análise da relação entre ciência e tecnologia, intitulada "modelo linear de inovação" a qual estabeleceu um novo paradigma de política e gestão científica e tecnológica, adotado no final da década de 1950 pela maioria dos países industrializados.

$\mathrm{Na}$ concepção linear, a mudança técnica era compreendida como uma seqüência hierárquica de estágios, onde se passava, de uma forma sucessiva, da pesquisa fundamental ou básica (ciência) para a pesquisa aplicada (tecnologia), e desta para o desenvolvimento experimental e consequente produção e comercialização (inovação).

Nesse processo novos conhecimentos advindos da pesquisa científica levariam a processos de invenção que seriam seguidos por atividades de pesquisa aplicada e desenvolvimento tecnológico, resultando ao final da cadeia, na introdução de produtos e processos comercializáveis (BUSH, 1945).

Para Viotti (2003), essa concepção introduz a perspectiva na qual a análise dos processos de produção, de uso e de difusão de CT\&I deve considerar a influência simultânea de aspectos institucionais e socioeconômicos, e estes ligados às diversas áreas do conhecimento. Com isso, a inovação se apresenta enquanto processo multidisciplinar, organizado, contínuo e permante.

Na década de 1980, em decorrência dos estudos de Kline e Rosenberg (1986) a concepção linear foi considerada superada, diante da alegação de que o processo de inovação não segue uma sequência hierárquica e não considera as interações entre ciência e tecnologia em seu desenvolvimento.

Assim, foi introduzido o modelo interativo do processo de inovação, também conhecido por modelo das "ligações em cadeia", o qual se atribui às empresas posição central no processo de inovação. Nesse modelo são estabelecidas interações entre o sistema de ciência e tecnologia e empresas, e entre as próprias empresas. A inovação é considerada um processo complexo de interações, as quais envolvem todos os agentes envolvidos nas diversas etapas do processo de inovação, quais sejam: empresas, instituições de pesquisa, universidade e mercado (Kline, Rosenberg, 1986).

Conforme consta do Manual de Oslo (1997) o processo de inovação combina as etapas científicas, tecnológicas, organizacionais, financeiras e comerciais que conduzem, ou visam conduzir, à implementação de inovações, incluindo também a atividade de P\&D. Nesse 
sentido, o modelo de cadeia considera a oportunidade de transformar as inovações de produtos e serviços em modelos de negócios.

Mantendo-se o foco na estruturação da gestão da inovação, Freeman (1987) sinaliza a necessidade de uma visão mais ampla do processo de inovação, inserindo-o no contexto de um sistema de inovação, formado por conjunto de atores e por um contexto institucional que determina o funcionamento do sistema e molda o comportamento dos atores. Essa estruturação, aparentemente mais completa e próxima da complexidade da realidade, se traduziu na abordagem sistêmica do processo de inovação a qual envolve uma rede de instituições, públicas e privadas, cujas interações e atividades iniciam, modificam e difundem novas tecnologias ( Freeman,1987).

No entanto, para os autores Davila, Epstein e Shelton (2007) pensar o processo de inovação implica em considerar a abordagem sistêmica atrelada à complexidade do processo de desenvolvimento de novos produtos, o qual envolve impulsionar o crescimento de receita da empresa e aumentar lucros, e concomitante melhorar as relações com os grupos de interesses e motivar funcionários. Logo, para os autores, a inovação precisa considerar a mistura entre o velho e o novo, suplantando o entendimento unísono de que para a criação de algo novo devese destruir o velho, e sua ocorrência necessita, antes de tudo, de boas idéias.

Nesse sentido, considerando que a inovação tem papel preponderante no êxito das empresas, os sistemas de gestão da inovação devem considerar a firmação de políticas, procedimentos e mecanismos de tratamento e gestão da informação e de ideias. Esses rumos propiciam a ocorrência da inovação sem tirar de foco o valor a ser gerado para o cliente, a capacidade de se visualizar novos segmentos preferenciais no mercado, de facilitar a interação da empresa com o sistema de ciência e tecnologia e grupos de interesse, além de amparar o processo de tomada de decisão organizacional (DAVILA, EPSTEIN, SHELTON, 2007).

Para a implantação de sistemas de gestão de inovação, segundo defendem Davila, Epstein e Shelton (2007), é necessário, antes de qualquer investimento financeiro, compromisso e disponibilidade, uma mudança cultural $^{9}$, pois, para se chegar à inovação, é necessário haver o gerenciamento de ideias. Segundo os autores a inovação deve ser visualizada como um fluxo que se inicia com uma enxurrada de ideias, as quais passam pelo processo de apreciação, seleção, investimento e execução, até que apenas as melhores ideias sejam direcionadas à comercialização.

\footnotetext{
${ }^{9}$ Vale lembrar Bauman (2001) quando cita que uma das características da modernidade líquida é a fluidez da estrutura, até então vigente, e que a mudança cultural é um dos principais meios que promovem e amparam o surgimento do novo.
} 
Essa percepção encontra amparo em Suaiden e Leite (2016) quando defendem que há, atualmente, uma nova forma de percepção da ciência, da tecnologia e da inovação, enquanto evoluções do conhecimento que extrapolam os conceitos e processos fundados na observação, método e experimentação, mas acrescentando a estes valores sociais e culturais os quais tomam forma no fluxo da realidade que os envolve.

Assim, a nova sistemática da inovação, criada por Davila, Epstein e Shelton (2007), inicia com fase criativa, a qual se caracteriza pela torrente de ideias criativas e acolhidas. Após esta fase, inicia-se o processo de seleção das ideias, sendo muitas delas rejeitadas. As ideias selecionadas recebem grande aporte de recursos e avançam para a etapa de execução. As ideias com potencial de se transformarem em propriedade intelectual avançam para a etapa da criação do valor, finalizando com a comercialização, se for o caso.

Diante do exposto, verifica-se que a concepção do processo de inovação tem evoluído, ao longo do tempo, a partir de modelos que tentam sistematizar a inovação.

Inicialmente, no modelo linear e hierárquico, o processo da inovação iniciava com a pesquisa fundamental passando para o estágio da pesquisa aplicada, chegando ao desenvolvimento do produto, e sua comercialização. No modelo das ligações em cadeia a inovação acontece a partir de um conjunto de interações e interdependências dentro e entre as empresas, e com os grupos de interesse. No modelo de abordagem sistêmica o processo de inovação se situa no quadro de um sistema de inovação, formado por atores e instituições interdependentes. E no modelo de Davila, Epstein e Shelton (2007), a inovação acontece a partir do fluxo de ideias, o qual transita evolutivamente pelos estágios da criação, gestão, disseminação, apropriação e comercialização.

Nesse sentido, é explícita a sintonia entre o entendimento dos autores Davila, Epstein e Shelton (2007) acerca do processo de inovação e a dinâmica contemporânea característica do novo paradigma econômico-tecnológico informacional, tratado anteriormente, na qual a produtividade e a competitividade de empresas, regiões e nações dependem basicamente da capacidade de se gerar, coletar, gerenciar e utilizar de forma eficiente informações, ideias e conhecimentos na geração da inovação.

Essa sintonia ampara e reforça o suposição de que o fluxo livre de informação, de ideias, bem como do conhecimento informal aquele formado nas práticas histórico-sócio-culturais, oriundo do cidadão comum, pode se revelar como uma ferramenta facilitadora para a ampliação da capacidade inovativa do País, no contexto da sociedade da informação. 


\section{Conclusão}

O artigo se propôs a lançar luz sobre a importância de se publicizar o processo de inovação no Brasil, trabalhando a seguinte hipótese: a coleta e a gestão de informações, de ideias e de conhecimento do cidadão comum pode se revelar uma ferramenta destinada à ampliação da capacidade inovativa do País, no contexto da sociedade da informação.

Foi possível verificar, ao longo do artigo, que a hipótese ora levantada encontra amparo teórico no novo paradigma econômico-tecnológico de informação que tem caracterizado a sociedade informacional segundo Castells (2009) e, no modelo do processo de inovação, definido por Davila, Epstein e Shelton (2007), que se inicia com um fluxo "torrencial" da criação, ou seja, a partir de muitas ideias as quais são apreciadas, algumas escolhidas e comercializadas.

Considerando que o novo paradigma informacional se caracteriza, entre outros aspectos, por uma estreita relação com o crescimento econômico a partir de inovações tecnológicas, sendo estas oriundas de uma dinâmica contemporânea, sistêmica, informal, nãolinear, tampouco hierarquizada, de se organizar, gerenciar e disseminar a informação e o conhecimento (Castells, 2009), percebe-se uma sintonia entre essa dinâmica e o modelo do processo de inovação defendido por Davila, Epstein e Shelton (2007) no qual a inovação pode surgir de um grande volume de ideias, considerando muitas vezes a mistura do passado, do histórico, da cultura e do presente, da contemporaneidade, as quais, após sua gestão e apropriação poderão ser levadas, ou não, à comercialização.

Desta forma, é possível verificar que o propósisto desse artigo se ampara na dinâmica contemporânea de Castells (2009), e no modelo do processo de inovação de Davila, Epstein e Shelton (2007). E, essa constatação lança luz sobre a importância de se publicizar a inovação no Brasil.

Cabe ressaltar, que essa confirmação enseja uma ruptura do padrão atual de exploração do conhecimento e de ideias, na geração do novo, vigente no Brasil, uma vez que, o aporte para a inovação, utilizado pelo Sistema Nacional de Ciência, Tecnologia e Inovação (SNCTI), tem como fonte específica de insumo, a academia e a empresa.

Entende-se, portanto, que, a não publicização do processo de coleta e gestão de uma ideia criativa, pode contribuir para a dificuldade de se inovar, no Brasil, pois apesar de iniciativas, leis e políticas de estímulo e investimento para a inovação é recorrente a preocupação em como se apropriar e transformar o conhecimento em práticas inovadoras ${ }^{10}$.

\footnotetext{
${ }^{10}$ Segundo o Relatório de Competitividade Global de 2012, o Brasil é o $53^{\circ}$ país do mundo em inovação, cinco posições acima da que ocupa no Índice Global de Inovação. We forum.
}

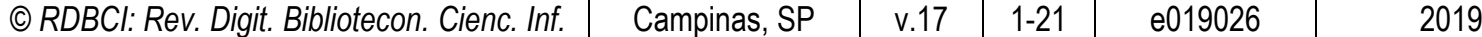


$\mathrm{Na}$ abertura da $68^{\mathrm{a}}$ Reunião Anual da SBPC, Julho/2016, o então Presidente do Conselho Nacional de Desenvolvimento Científico e Tecnológico - CNPq relatou ser necessário traçar um caminho para o avanço da inovação, uma vez que o Brasil é um país cujo depósito de patentes é pequeno, apresenta baixa participação de empresas brasileiras, dispõe de uma produção científica concentrada em poucas universidades e o aumento na quantidade de publicações não reflete em sua relevância. No mesmo mês, a Mobilização Empresarial pela Inovação entregou ao então Ministro da Ciência, Tecnologia, Inovações e Comunicações documento com propostas e incentivos legais para impulsionar a inovação, tratada com a chave para o crescimento econômico.

Nesse sentido, vale inserir no rol de possibilidades para ampliação da capacidade inovativa do Brasil, a participação do cidadão comum. Lembrando que uma das maiores empresas do mundo - facebook - nao foi criada por nenhuma empresa ou cientista, mas sim por estudantes universitários.

Segundo Manuel Castells, essa dinâmica contemporânea tem caracterizado a sociedade da informação, a qual estabelece a formação e uso das redes sociais como um novo padrão para relacionamentos entre indivíduo de uma sociedade e para a troca de conhecimentos, ideias e de informações.

\section{Referências}

ALBAGLI, Sarita. Conhecimento, inclusão social e desenvolvimento local. Pesquisa Brasileira em Ciência da Informação e Biblioteconomia, 2006. Disponível em: http://repositorio.ibict.br/bitstream/123456789/100/1/albagliIS122006.pdf. Acesso em: 10 jun. 2016.

ALBAGLI, Sarita; Maciel, Maria Lúcia, Informação e conhecimento na inovação e no desenvolvimento local. Ciência da Informação, 2004. Disponível em: http://www.scielo.br/pdf/ci/v33n3/a02v33n3. Acesso em: 10 jun. 2016.

ANDRÉ, Isabel; ABREU Alexandre. Dimensões e espaços da inovação social. Finisterra, 81, p. 121-141, 2006.

BOURDIEU, Pierre. A “juventude” é apenas uma palavra. In: QUESTÕES de sociologia. Rio de Janeiro: Marco Zero, 1983.

CASTELLS, Manuel. A Sociedade em Rede. São Paulo: Paz e Terra, 1999. [v. I de A Era da Informação: economia, sociedade e cultura].

CEZAR, Kilma Gonçalves; GOMES, Cristiane Barreto; PERSEGONA, Marcelo Felipe Moreira. A inovação como dimensão socioeconômica do conhecimento. RDBCI: Revista Digital de Biblioteconomia e Ciência da Informação. Campinas, v. 9, n.1, p.209-224, 2011.

\begin{tabular}{l|l|l|l|l|l|}
\hline (C) RDBCl: Rev. Digit. Bibliotecon. Cienc. Inf. & Campinas, SP & v.17 & $1-21$ & e019026 & 2019 \\
\hline
\end{tabular}


Disponível em: http://www.sbu.unicamp.br/seer/ojs/index.php/rbci/article/view/500. Acesso em: 10 jun. 2016.

CHIARINI, Túlio; VIEIRA, Karine. Universidades como produtoras de conhecimento para o desenvolvimento econômico: sistema superior de ensino e as políticas de CT\&I Revista Brasileira Economia. v.66, n.1 Rio de Janeiro Jan./Mar. 2012 http://dx.doi.org/10.1590/S0034-71402012000100006.

COTEC (Fundación para la Innovación Tecnológica). Pautas metodológicas en gestión de la tecnologia y de la innovación para empresas. Tomo 1. Módulo I. "Introducción, Presentación, CD y Módulo I: perspectiva empresarial” - TEMAGUIDE. 1999. $60 \mathrm{p}$ http://www.bookcrossing.com/journal/8097229/ .

DAGNINO, Renato. (Org) Tecnologia Social: Ferramenta para construir outra Sociedade. Campinas: Unicamp, 2009.

DAGNINO, Renato. (Org) A tecnologia social e seus desafios. In: Tecnologia social. Uma estratégia para o desenvolvimento. Fundação Banco do Brasil, Rio de Janeiro, 2004. .

DAGNINO, Renato. (Org) A tecnologia social no Brasil. In. Tecnologia social: ferramenta para construir outra sociedade. DAGNINO, Renato Peixoto (Org.) Campinas, SP: IG/UNICAMP, 2009.

DAVENPORT, T.; PRUSAK, L. Conhecimento Empresarial: como as organizações gerenciam seu capital. 12. ed. Rio de Janeiro: Elsevier, 2003.

DAVENPORT, Thomas; PRUSAK, Laurence. Working knowledge: how organizations manage what tehy know. Boston: Havard Business Schol Press, 1998.

DAVILA, T.; EPSTEIN, M. J.; SHELTON, R. As regras da inovação - como gerenciar, como medir e como lucrar. Porto Alegre: Bookman, 2007.

FREITAS FILHO Fernando Luiz. Gestão da Inovação: teoria e prática para implantação. São Paulo: Atlas, 2013.

HAKLAY, M. 2013. Citizen Science and Volunteered Geographic Information: overview and typology of participation, p.105-122. In: Sui, D.; Elwood, S. \& Goodchild, M. Crowdsourcing Geographic Knowledge: Volunteered Geographic Information (VGI) in Theory and Practice. Springer. 410p.

LASTRES, Helena \& CASSIOLATO, José Eduardo Novas Políticas da Era do Conhecimento: o foco em arranjos produtivos e inovativos. Parcerias Estratégicas - Centro de Gestão e Estudos Estratégicos n. 17 . Brasília: CGEE. 2003

LALL, Somik V.; GHOSH, Sudeshna. Learning by dining: informal networks and productivity in Mexican industry : [S. 1.] : World Bank Development Research Group, 2002. 
http://www.wds.worldbank.org/external/default/WDSContentServer/WDSP/IB/2002/03/22/0 00094946_0203070403327/Rendered/PDF/multi0page.pdf. Acesso em: 15 maio 2016.

MORIN, Edgard. A Noção de sujeito. In: SCHNITMAN, D. F. (Org.). Novos paradigmas: cultura e subjetividade. Porto Alegre: Artes Médicas, 1996.

MUELLER, Suzana Pinheiro. Popularização do conhecimento científico. Data Grama Zero Revista de ciência da informação. v.3. n.2, p.1-11, 2002. Disponível em:

http://dici.ibict.br/archive/00000315/01/Popularização_do_conhecimento_científicofico.pdf. Acesso em: 15 maio 2016.

NICOLSKY, Roberto. Inovação tecnológica: o novo paradigma - Ciência e Tecnologia para o Século XXI: o desenvolvimento científico e tecnológico do Brasil e do Mercosul. São Paulo: Calábria, 1999.

NONAKA, Ikujiro; TAKEUCHI, Hirotaka. Criação de conhecimento na empresa: como as empresas japonesas geram a dinâmica da inovação. Rio de Janeiro: Campus, 1997.

OCDE. Managing National Innovation Systems; 1999 Paris.

Ruttan, Vernon. La teoría de la innovación inducida del cambio técnico en el agro de los países desarrolados. In: Cambio técnico en el agro latinoamericano. San José, Costa Rica, Piñeiro y Trigo, IICA, 1985.

SCHUMPETER, Joseph Allois. O Fenômeno Fundamental do Desenvolvimento. In: Teoria do Desenvolvimento Econômico. São Paulo: Abril Cultural. p. 43-66. [Col. Os Economistas], 1982.

SCHUMPETER, Joseph Allois. Capitalismo, Socialismo y Democracia Capítulo VII - El Processo de la Destruction Creadora., Madrid: Aguilar S.A. de Ediciones, p.121, 1952

SOLOW, Robert. Learning from 'Learning by Doing': Lessons for Economic Growth (Kenneth J. Arrow Lectures) Hardcover, 1997 https://books.google.com.br/books?id=VLR09gb05XIC\&printsec=frontcover\&hl=pt$\underline{B R \& \text { source }=\mathrm{gbs} \_g e \_s u m m a r y \_r \& c a d=0 \# \mathrm{v}=\text { onepage } \& \mathrm{q} \& \mathrm{f}=\text { false. }}$. Acesso em: 15 maio 2016.

SUAIDEN, Emir José e OLIVEIRA, Cecília Leite: Cultura da Informação: os valores na construção do conhecimento Curitiba: CRV, 2016.

SVEIBY, Karl Erik. A Nova Riqueza das Organizações. Rio de Janeiro: Campus, 1998.

VASCONCELOS, Marco Antonio; GARCIA, Manuel Enriquez. Fundamentos de economia . São Paulo: Saraiva, 1998.

VIOTTI, Eduardo Baumgratz. Fundamentos e evolução dos indicadores de CT\&I. In: VIOTTI,E. B.; MACEDO, M. M. (Org.). Indicadores de ciência, tecnologia e inovação no Brasil. Campinas: Editora da UNICAMP, 2003. 


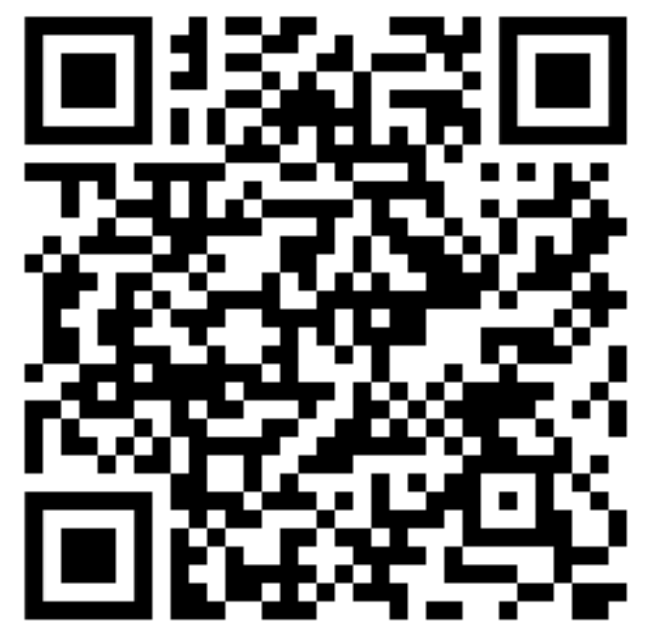

